\title{
EFFECT OF MOTORING VOLTAGE ON COMPRESSION RATIO OF A FREE-PISTON LINEAR GENERATOR ENGINE
}

\author{
Ezrann Z. Zainal A. ${ }^{\text {** }}$, Abdulwehab A. Ibrahim ${ }^{2}$, A. Rashid A. Aziz ${ }^{1}$ and \\ Saiful A. Zulkifli ${ }^{1}$ \\ ${ }^{1}$ Centre for Automotive Research and Energy Management, \\ Department of Mechanical Engineering, Universiti Teknologi PETRONAS, \\ 32610 Bandar Seri Iskandar, Perak, Malaysia. \\ ${ }^{2}$ INTI International University, \\ ${ }^{2}$ Persiaran Perdana BBN, 71800 Nilai, Negeri Sembilan, Malaysia. \\ *E-mail: ezrann.zharif@gmail.com; Phone: +605-368 8103
}

\begin{abstract}
The need for alternative power sources is crucial because of the increase in global energy demand and stringent emission regulations. The free-piston linear generator engine is one of the main alternatives thanks to its high efficiency, wide operating range and low emissions. However, low compression pressure which produces low power generation is an obstacle to its development. In order to increase compression pressure, further development of the motoring process is required. The study investigated the effect of motoring voltage in compression pressure and compression ratio. Motoring voltages varied from $36 \mathrm{~V}$ to $84 \mathrm{~V}$. Higher motoring voltage increased piston speed up to $2 \mathrm{~m} / \mathrm{s}$ which reduced the air leakage and thus produced a sharper $\mathrm{p}-\mathrm{V}$ profile and higher compression pressure. An inverse relationship between the compression ratio and compression pressure during motoring was also observed.
\end{abstract}

Keywords: Free-piston linear generator; Compression ratio, In-cylinder pressure; Motoring voltage.

\section{INTRODUCTION}

\section{Free-Piston Linear Generator Engine}

The world energy demand will increase by $36 \%$ from 2008 to 2035 [1, 2]. However, the growing energy demand from fossil fuels has increased $\mathrm{CO}_{2}$ emissions exponentially from nearly zero in 1870 to over $32 \mathrm{GtCO}_{2}$ in 2011. Emissions from the road sector alone have contributed a 52\% increase since 1990 and accounted for about threequarters of transport emissions in 2011. The World Energy Outlook 2013[3] projects that transport fuel demand will grow by nearly $40 \%$ by 2035 [4]. Hence, an intensive effort is being made by governments and researchers to devise a new power generation unit with high power output and low emissions. The development of the free-piston engine was conceived 80 years ago but its development only began after it was found that the engine has the potential to reduce emissions and it can overcome the challenges of obtaining a variable compression ratio that cannot be achieved with conventional engines [5].

The most significant advantage of a free-piston linear generator engine (FPLG) is that it offers high efficiency with low emissions [6-8]. This is achievable because of 
its free-piston characteristics whereby during combustion the piston stays a shorter time at top dead cener (TDC) than a conventional crank engine. This reduces heat loss and lowers the combustion temperature, thus producing low NOx. Van Blarigan [9] measured the thermal efficiency of an FPLG at 56\% with low NOx emissions compared with the conventional crank engine whose efficiency is lower than $40 \%$. Fredriksson [10] found similar characteristics and showed that most combustion occurred at fast expansion rate and below $1800 \mathrm{~K}$ which is enough to ensure an ultra-low level of NOx. Additionally, coupling it with direct injection (DI) further reduced the amount of unburned fuel during the scavenging process. Goldsborough [11] observed that with DI, low intake temperature and a uniflow combustion chamber, the FPLG optimizes the efficiency and emission characteristics of the engine. Furthermore, the missing mechanical links of crankshafts and camshafts reduce the friction and at the same time introduce flexibility in terms of stroke and compression ratio, which increases its efficiency [12].

An FPLG engine is based on a free-piston engine whereby the piston moves freely without any mechanical factor limiting its motion. It was designed and fabricated by the Universiti Teknologi PETRONAS (UTP) FPLG team. It is a crank-less reciprocating engine with no mechanical output and experiences less mechanical friction. Because of the absence of the crankshaft, the side load friction from the piston skirt is reduced, resulting in high mechanical efficiency. Its simple design contains fewer parts, it is less costly, less maintenance is required and it is more reliable. Because of its compact design, it has a high power to weight ratio $[13,14]$. The FPLG working principle is based on a two-stroke cycle whereby it operates as a motor during starting/cranking mode. Hydrogen is injected directly into the combustion chamber and the air and fuel mixture is combusted by a spark plug. The combustion energy pushes the piston towards the other end and the process repeats itself. The back and forth motion of the translator (which consists of a permanent magnet assembly as shown in Figure 1 cuts the magnetic fields to produce electricity [15].

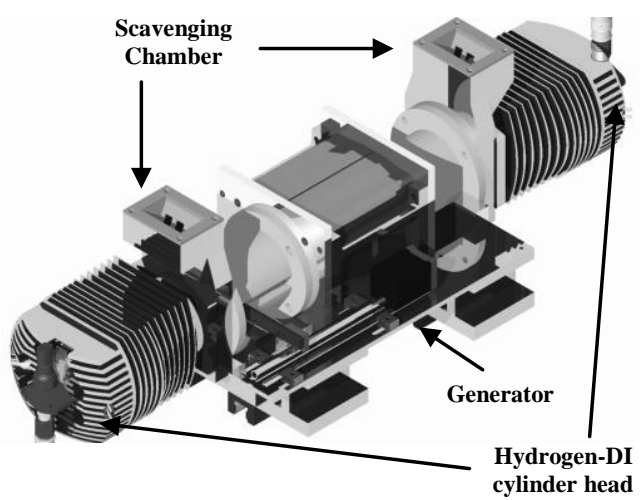

(a)

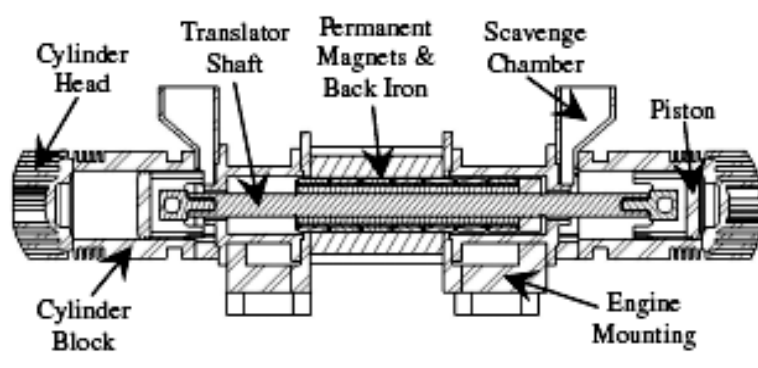

(b)

Figure 1. UTP FPLG (a) FPLG prototype (b) Cross-sectional view of UTP FPLG.

\section{Starting of a Free-piston Linear Generator Engine}

The absence of a flywheel in a free-piston engine is an obstacle to be overcome. The flywheel is required to start and stabilize cyclic variations in an internal combustion engine and also enables energy storage. Thus, a different starting strategy is necessary 
in a free-piston engine. A starting method was proposed [16] for a free-piston engine, which required starting or igniting at the first cycle by impulsing the piston. A common starting strategy which is commonly applied in large engines is to push the piston towards the top, dead center, and then supply high-pressured air rapidly into the bounce chamber to push the piston to the highest velocity possible. This strategy is widely applied in free-piston air compressors and gasifiers as well. As regards hydraulic freepiston engines, starting is achievable with a hydraulic pump. Many starting problems arise with the free-piston linear generators. A number of starting methods using an electric motor have been implemented $[17,18]$ and a spring-mass system for starting the engine was proposed in [19]. A two-stroke spark-ignited free-piston linear generator engine prototype was designed and built for research purposes at West Virginia University (WVU). A pair of starter solenoid coils were taken from a heavy-duty engine and attached to the connecting rod to start the engine [20]. The mechanism worked successfully in terms of improving the motoring force for the prototype but more space was required to place the solenoids. Experiments were carried out and the conclusion drawn was that unthrottled operation of the engine was desirable for the spark-ignited prototype to ease the engine operation and thus the next step was to develop a new diesel type for a free-piston linear generator [21]. The second version of the engine, the diesel prototype with an alternator as a motoring device, could not work because of a problematic starting process which caused a number of transistors to burn out.

Motoring speed was also a crucial factor for the creation of the FPLG. It was reported that the initial velocity of the piston (motoring velocity) is very important because it influences the escaping velocity (expansion velocity) during the expansion and the following combustion process [22]. The escaping velocity determines the initial velocity for the opposite cylinder in the successive cycle. Overall, higher piston velocity increases the engine speed. Spark timing was also seen to be retarded at first and later to advance because of the increase in engine speed after combustion is initiated; this is attributed to the piston stroke change with respect to the piston initial velocity. The prototype efficiency increased as the piston initial velocity increased because of a higher compression ratio. It was noted that higher indicated mean effective pressure (IMEP) was desirable for increasing the potential energy since the piston kinetic energy was directly proportional to the IMEP value and thus higher initial velocity (motoring velocity) produces higher IMEP. This was proved when the highest IMEP produced was at $0.49 \mathrm{MPa}$ at $4 \mathrm{~m} / \mathrm{s}$ initial piston velocity compared with a lower initial velocity at 1.5 $\mathrm{m} / \mathrm{s}$ and $2 \mathrm{~m} / \mathrm{s}$ which produced $0.35 \mathrm{MPa}$ and $0.45 \mathrm{MPa}$ respectively [22]. Hence, higher motoring speed is necessary for the FPLG starting strategy, as it leads to a higher compression ratio and higher power output.

\section{EXPERIMENTAL SET UP}

\section{Design of Experiment}

The experiment was performed on a two-stroke, direct injection, loop scavenge, UTP free-piston linear generator engine with two opposed combustion chambers, with 76 $\mathrm{mm}$ bore, $34.5 \mathrm{~mm}$ nominal stroke length and $333 \mathrm{cc}$ engine capacity. For starting of FPLG, is it motored whereby current from the battery bank was injected into the coils to produce force to reciprocate the translator against the forces of compression of the engine blocks in order to produce combustion. A control and data acquisition (DAQ) system based on National Instruments (NI) hardware and software was used to control 
the engine and to log data during experimentation, as shown in Figure 2. Data logging was performed at a $10 \mathrm{kHz}$ sampling rate to attain accurate results for data postprocessing. The data acquisition system, cylinder pressure, current induced into the coils and corresponding piston linear displacement were used to gather data for the left and right cylinders. For current injection and inverter switching purposes, a signal from the control system was amplified by the gate driver to operate the MOSFET inverter. During the motoring experiments, the battery voltage which was derived from a number of $12 \mathrm{~V}$ automotive lead acid batteries was connected in series. The battery quantity varied from a minimum of three pieces to a maximum of seven pieces of $12 \mathrm{~V}$ batteries which produced $36 \mathrm{~V}, 60 \mathrm{~V}, 72 \mathrm{~V}$ and $84 \mathrm{~V}$ respectively to provide electrical energy to the FPLG during the motoring and starting process. The maximum allowable voltage was $90 \mathrm{~V}$ because of the voltage rating of the MOSFET inverter. It was not possible to connect an additional battery to the battery bank since it would total $96 \mathrm{~V}$, which is more than allowable. Step by step increments of motoring voltage were made in order to identify the prototype's steady-state behavior before experimenting with higher voltage. An automotive battery was chosen in order to replicate the application of charging and discharging (motoring) process on board a Series Hybrid Electric Vehicle (SHEV) battery bank.

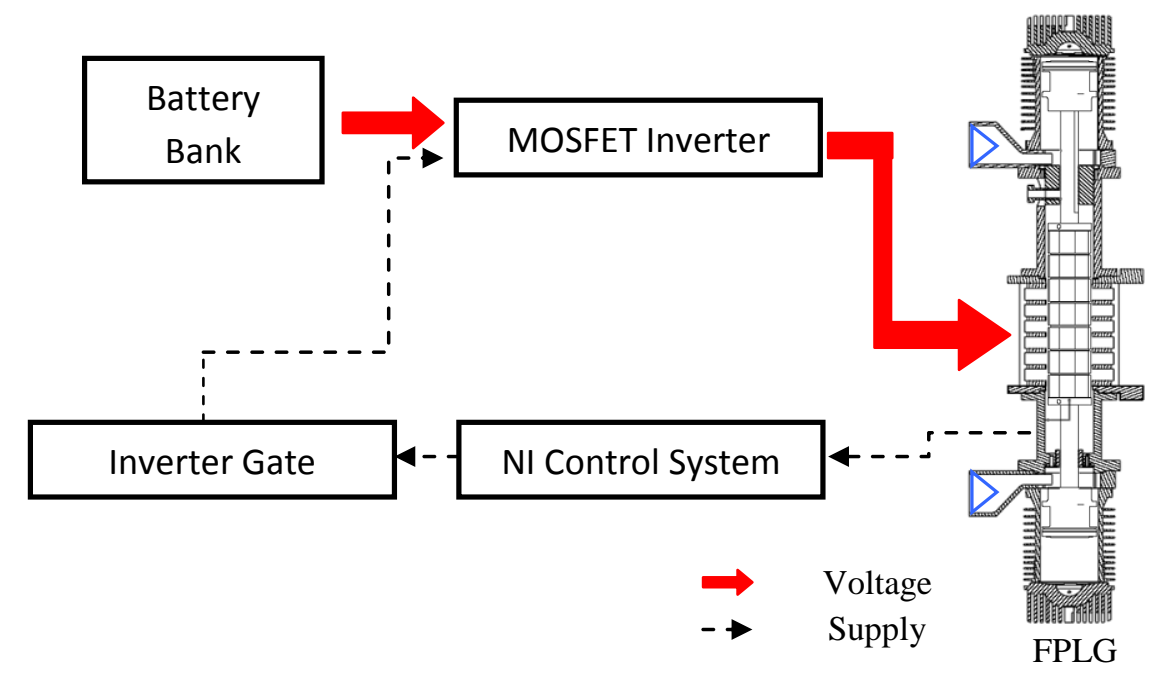

Figure 2. FPLG experimental setup for motoring experimental works.

\section{RESULTS AND DISCUSSION}

\section{Motoring FPLG}

Higher compression pressure during the motoring process increased the performance of combustion pressure, thus producing higher power generation. According to Zulkifli [14], motoring with a higher battery voltage (which is related to higher motoring resultant force) allows the engine to motor at full amplitude (higher compression ratio) to achieve higher compression pressure. Hence, an experiment was performed to motor FPLG using $36 \mathrm{~V}, 60 \mathrm{~V}, 72 \mathrm{~V}$ and $84 \mathrm{~V}$ respectively, as shown in Figure 3. Figure 3 shows motoring of FPLG using MOSFETs by varying the battery capacity from $36 \mathrm{~V}$ to $84 \mathrm{~V}$. It can be seen that $84 \mathrm{~V}$ has the highest compression pressure of 7.58 bar, followed by $72 \mathrm{~V} 7$ bar, $60 \mathrm{~V} 5.43$ bar and $36 \mathrm{~V} 3.85$ bar respectively. It is also evident that at $84 \mathrm{~V}$ pressure reaches 7.58 bar at $27.5 \mathrm{~mm}$ which is earlier than other voltages, 
indicating higher compression peak pressure at shorter stroke (lower TDC). Motoring at a higher battery capacity achieves high pressure earlier and can be seen from the pressure peak point. This is because higher battery capacity/motoring voltage produces higher piston velocity which decreases air leakage through the piston rings [23].

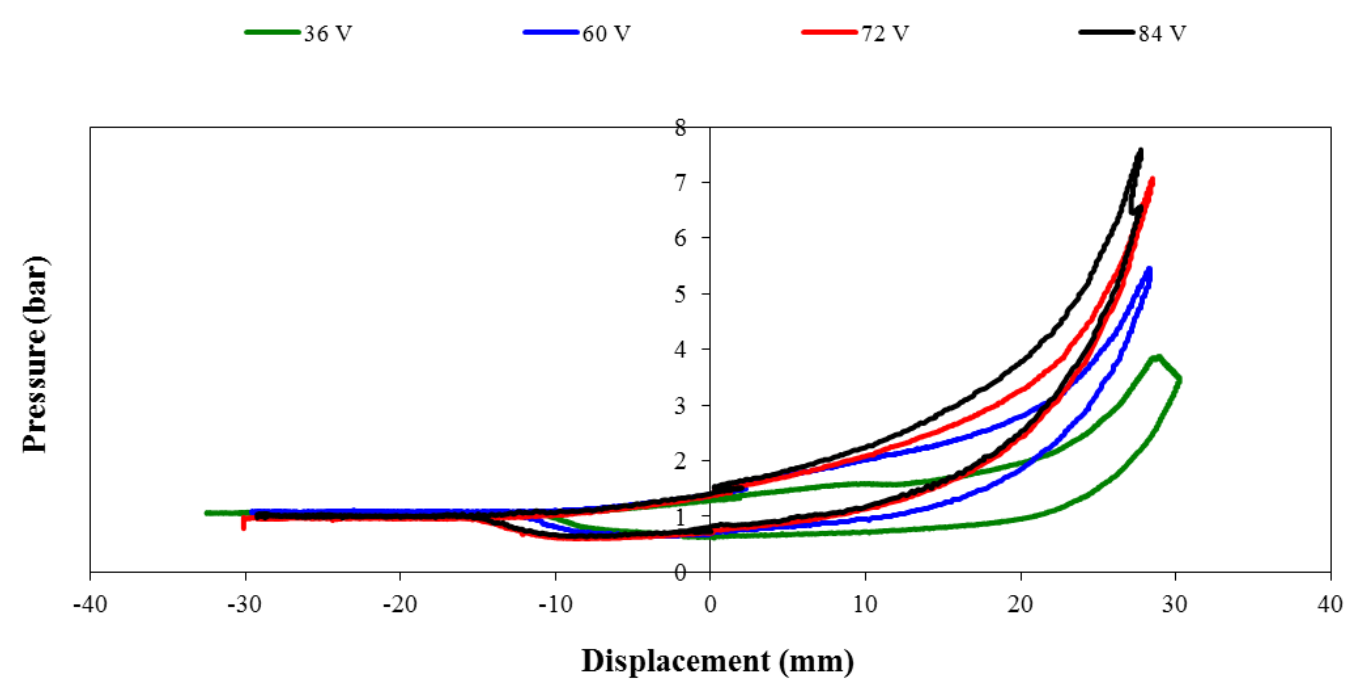

Figure 3. Motoring comparison for various battery capacities.

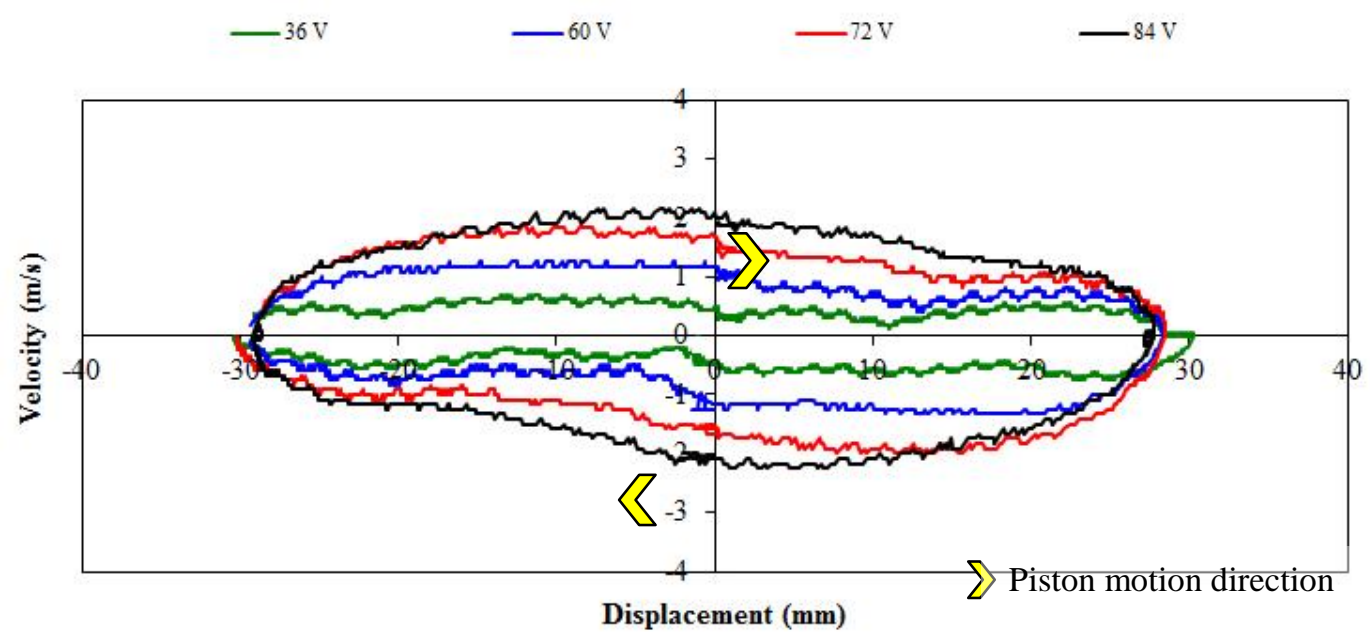

Figure 4. Motoring comparison of piston velocity by varying battery capacities.

Motoring with $84 \mathrm{~V}$ records the highest piston velocity at $2 \mathrm{~m} / \mathrm{s}$, followed by 72 $\mathrm{V} 1.6 \mathrm{~m} / \mathrm{s}, 60 \mathrm{~V} 1.1 \mathrm{~m} / \mathrm{s}$ and $36 \mathrm{~V} 0.5 \mathrm{~m} / \mathrm{s}$, as shown in Figure 4 . The velocity profile at both ends represents an expansion and compression profile whereby piston velocity decreases towards the end because of resistance during compression stroke and change of direction. Motoring with a higher battery capacity is able to produce higher compression pressure as less air is leaked through the piston rings during high piston velocity motion [23]. One author observed that with $2 \mathrm{~m} / \mathrm{s}$ piston velocity during motoring, the expected piston expansion velocity is $3.25 \mathrm{~m} / \mathrm{s}$, which produces $0.45 \mathrm{MPa}$ IMEP. Depending on the type of fuel used, the optimum motoring velocity range is from $2.5 \mathrm{~m} / \mathrm{s}$ to $3.5 \mathrm{~m} / \mathrm{s}$. Fuels with a slower burning rate are suitable for lower motoring speed but faster motoring speed requires a faster burning rate of fuel [22]. In 
Figure 4, the maximum velocity recorded is $2 \mathrm{~m} / \mathrm{s}$ and a slower burning fuel is suitable for use at this speed; the expected expansion speed is $3.25 \mathrm{~m} / \mathrm{s}$. However, a modification of the inverter drive is required in order to exceed piston velocity higher than $2 \mathrm{~m} / \mathrm{s}$.

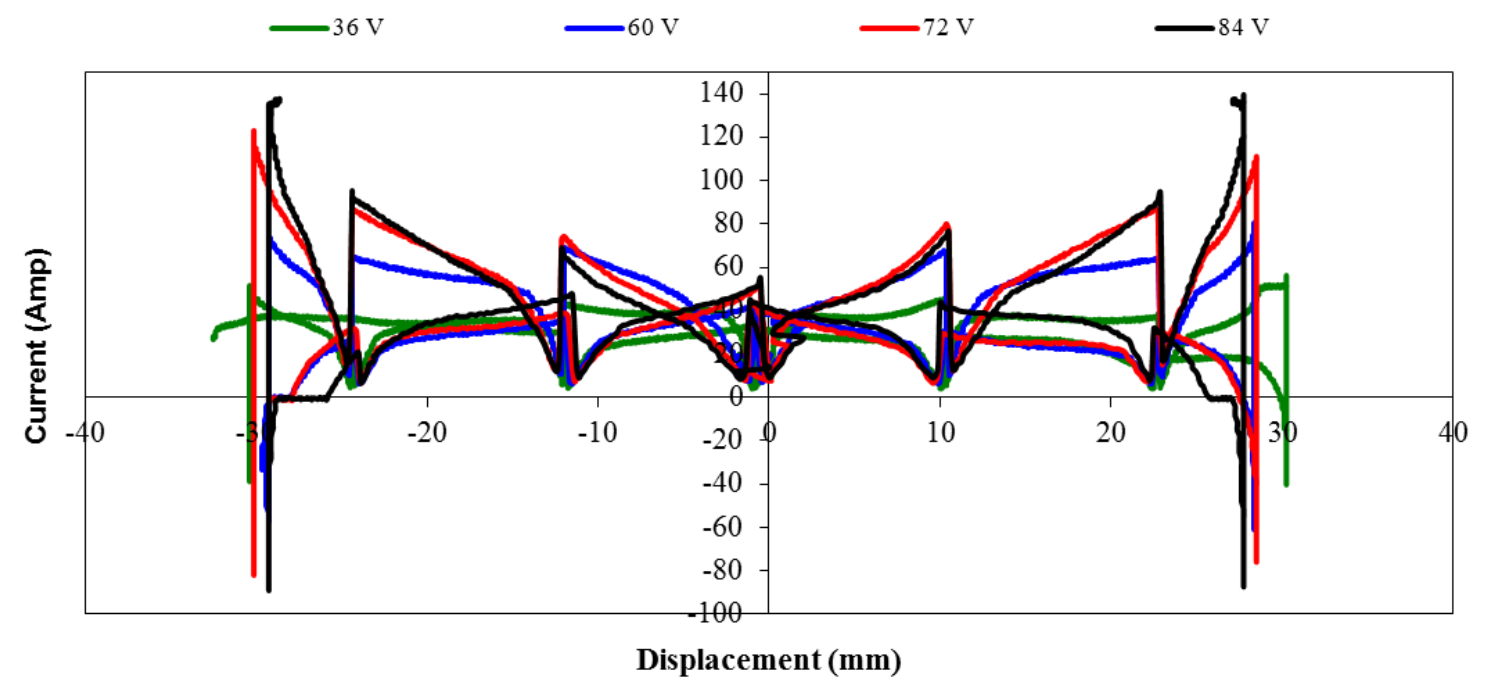

Figure 5. Variation of current against displacement with motoring conditions for various battery capacities.

Figure 5 shows four types of current profile. As the battery capacity increases, the total current induced increases, thereby revealing differences in the profile. The biggest difference can be seen at the end of every stroke (TDC). The point mentioned represents the highest resistance force towards the piston (compression stroke), as a result of which the current reaches its peak. Immense profile difference can also be seen at the end of every stroke for $36 \mathrm{~V}, 60 \mathrm{~V}$ and $72 \mathrm{~V}$ and few differences between $72 \mathrm{~V}$ and $84 \mathrm{~V}$. This is because the hardware restricts the maximum current flow.

\section{Relation between battery capacity, compression ratio and in-cylinder pressure}

According to Zulkifli [14], motoring with higher battery capacity (higher voltage) reciprocates FPLG to a higher compression pressure and compression ratio. This theory is also supported by [22] in that higher motoring velocity (initial velocity) produces less clearance volume which relates to higher compression ratio. The experimental works presented had a different outcome, however. It is assumed inter alia that the piston leakage model in the simulation works is not included or has a different profile.

Figure 6 shows two types of graph which explain how peak pressure and effective compression ratio are affected by battery capacity during motoring. Peak pressure reacts linearly with battery capacity, higher battery capacity produces higher cylinder peak pressure and the inverse relation holds for the effective compression ratio since increase in battery capacity reduces it. Higher battery capacity increases the piston speed and hence reduces air leakage through piston rings, thus producing higher compression pressure at earlier displacement. Less air leakage increases the engine's effectiveness in terms of absorbing and releasing energy during the reciprocation process. Achieving high compression pressure at earlier displacement significantly decreases the effective compression ratio. 


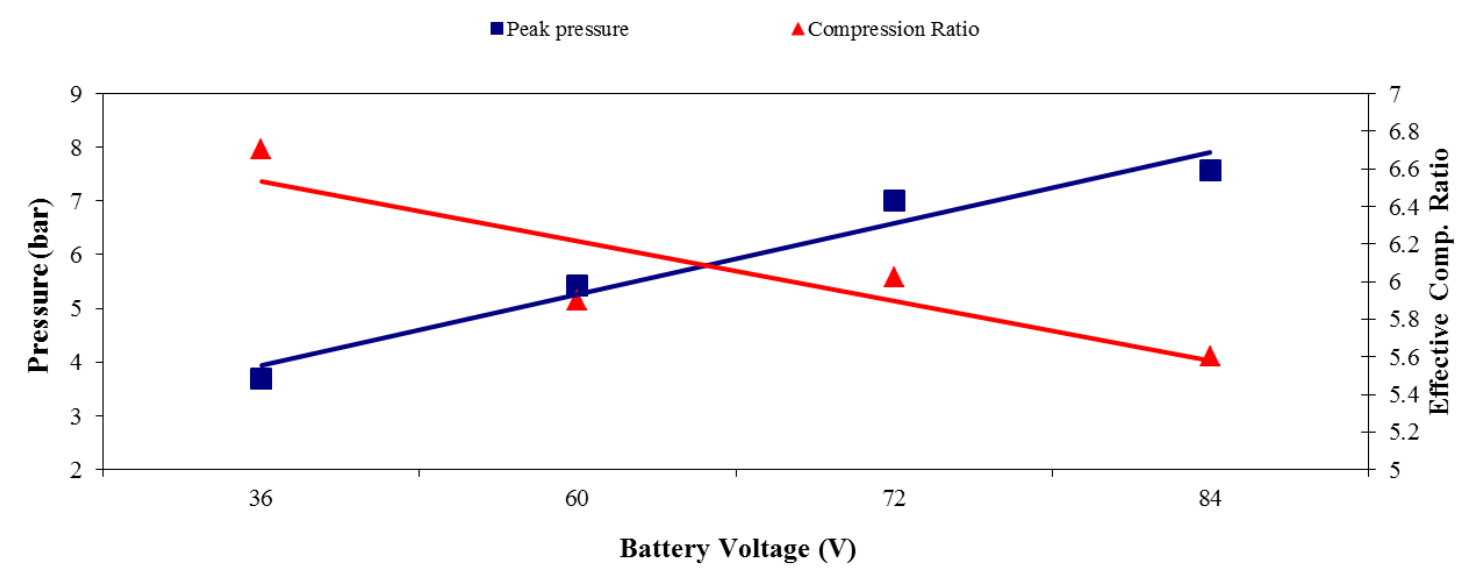

Figure 6. Relation between peak pressure and effective compression ratio.

\section{CONCLUSIONS}

In this paper, it is proven that motoring with higher battery voltage increases the compression pressure $(\max 8$ bar) and piston speed $(\max 2 \mathrm{~m} / \mathrm{s})$ but reduces stroke length, thus lowering the effective compression ratio. Increase in $133.33 \%$ motoring voltage results in a $300 \%$ increase in piston velocity and a $96.89 \%$ increase in compression pressure. However, the compression ratio reduces by $16.41 \%$. The maximum piston velocity achieved is at $2 \mathrm{~m} / \mathrm{s}$ at $84 \mathrm{~V}$ but the lowest compression ratio is achieved at $5.6 \mathrm{~V}$. This phenomenon is caused by reduced air leakage through piston rings at high piston speed and motoring voltage; this produces higher pressure but cannot overcome maximum pressure of 8 bar in order to produce a higher compression ratio. The inverse relation between compression ratio and battery voltage was also discovered. Hardware modifications are required in order to motor higher than $2 \mathrm{~m} / \mathrm{s}$.

\section{ACKNOWLEDGEMENTS}

The authors would like to thank the Universiti Teknologi PETRONAS and Malaysia Ministry of Education for providing grant with grant number PRGS/1/12/TK01/UTP/02/01 and facilities for the research.

\section{REFERENCES}

[1] Kweon JH, Jung JW, Kim TH, Choi JH, Kim DH. Failure of carbon compositeto-aluminum joints with combined mechanical fastening and adhesive bonding. Composite Structures. 2006;75:192-8.

[2] EIA. Annual Energy Outlook. US Energy Information Administration; 2010.

[3] IEA, EVI. Global EV Outlook. In: Trigg T, Telleen P, editors. Understanding the electric vehicle landscape to 2020. Paris, France: IEA and EVI, Clean Energy Ministerial; 2013. p. 41.

[4] IEA. $\mathrm{CO}_{2}$ Emissions from fuel combustion. 2013 Edition. 2013.

[5] Abdulwehab A. Ibrahim, Ezrann Zharif B. Zainal Abidin, Rashid A. Aziz, Zulkifli SA. Effect of injection timing on the operation of hydrogen-fuelled freepiston linear generator engine during starting. International Journal of Automotive Engineering. 2013;4:47-53. 
[6] Rahman MM, Ariffin AK. The role of nitriding on the fatigue life of a new free piston engine component: Finite element based investigation. Mechanical Engineering Research Journal. 2005;5:11-5.

[7] Rahman MM, Ariffin AK, Jamaludin N, Haron CHC. Durability assessment of a new free piston spark ignition engine: A computational approach. Jurnal Teknologi (Sciences and Engineering). 2006;45:81-102.

[8] Rahman MM, Ariffin AK, Rejab MRM, Kadirgama K, Noor MM. Multiaxial fatigue behavior of cylinder head for a free piston linear engine. Journal of Applied Sciences. 2009;9:2725-34.

[9] Peter Van Blarigan, Nicholas Paradiso, Scott Goldsborough. Homogeneous charge compression ignition with a free piston: a new approach to ideal otto cycle performance. SAE Technical Paper No. 982484; 1998.

[10] Fredriksson J, Denbratt I. Simulation of a two-stroke free piston engine. SAE Technical Paper No. ; 2004.

[11] Goldsborough SS, Fitzgerald J. Design and operational characteristics of a novel floating-stroke, free piston internal combustion reciprocating engine. SAE Technical Paper 2003-01-0001. 2013.

[12] Goertz M, Peng L. Free piston engine its application and optimization. SAE Technical Paper No. 2000-01-0996; 2000.

[13] Zulkifli SA, Karsiti MN, A-Aziz AR. Investigation of linear generator starting modes by mechanical resonance and rectangular current commutation. IEEE International Conference on Electric Machines and Drives. 2009;425-33.

[14] Zulkifli SAbM. Modeling, simulation and implementation of rectangular commutation for starting of free-piston linear generator.: Universiti Teknologi PETRONAS, Malaysia; 2007.

[15] Hanipah MRB. Combustion process in a two-stroke, $\mathrm{H}_{2}$-DI linear generator freepiston engine during starting. Universiti Teknologi PETRONAS, Malaysia; 2008.

[16] G. Flynn. Some principles and applications of the free-piston engine. General Motors Engineering Journals. 1958: 22-7.

[17] Zulkifli SA, Karsiti MN, Aziz AA. Starting of a free-piston linear enginegenerator by mechanical resonance and rectangular current commutation. Vehicle Power and Propulsion IEEE Conference. 2008;1-7.

[18] Cawthorne WR. Optimization of a brushless permanent magnet linear alternator for use with a linear internal combustion engine. West Virginia University: West Virginia University; 1999.

[19] K.D. Annen, D.B. Stickler, Woodroffe J. Miniature internal combustion engine (MICE) for portable electric power. Proceedings of the 23rd Army Science Conference, Florida. 2002.

[20] Nandkumar S. Two-stroke linear engine. West Virginia University: West Virginia University; 1998.

[21] Houdyschell D. A diesel two-stroke linear engine. Morgantown, West Virginia: West Virginia University; 2000.

[22] Kim J, Bae C, Kim G. Simulation on the effect of the combustion parameters on the piston dynamics and engine performance using the Wiebe function in a free piston engine. Applied Energy. 2013;107:446-55.

[23] Toth-Nagy C. Linear engine development for series hybrid electric vehicles. West Virginia University: West Virginia University; 2004. 